\title{
The effect of a newly developed mini-light-emitting diode catheter for interstitial photodynamic therapy in pancreatic cancer xenografts
}

\author{
So-Young Kim ${ }^{1 \dagger}$, Eun A. Cho ${ }^{2 \dagger}$, Sang Mun Bae ${ }^{3}$, Sang-Yeob Kim ${ }^{2^{*}}$ and Do Hyun Park ${ }^{4^{*}}$ (D)
}

\section{To the Editor}

The incidence of and mortality due to pancreatic cancer, with a low rate of response to chemotherapy or radiotherapy, are increasing worldwide [1-4]. Photodynamic therapy (PDT) has already been approved by the Food and Drug Administration and has been used in clinical trials for oncological treatment, including that for pancreatic cancer [5]. PDT is widely applied for promoting selective tumor necrosis or apoptosis using light after administering a photosensitizer [4]. Chemotherapy after PDT might occasionally lead to tumor downstaging, thereby allowing an attempt at surgical resection or $\mathrm{R} 0$ resection in patients with locally advanced pancreatic cancer [4]. For delivering light, the percutaneous approach might be uncomfortable for patients and requires passing the fiber laser until a long distance from pancreatic mass. Therefore, endoscopic ultrasound (EUS)-guided interstitial PDT (i-PDT) might be an optimal modality to deliver PDT to the pancreas mass $[3,4]$. A recent consensus statement from an expert panel for PDT use in pancreatic cancer also recommended that 1 )

\footnotetext{
*Correspondence: sykim3yk@amc.seoul.kr; dhpark@amc.seoul.kr

${ }^{\dagger}$ So-Young Kim and Eun A. Cho authors equally contributed as the co-first authors

2 Department of Medical Science, Asan Medical Center, University of Ulsan College of Medicine, Seoul, Korea

${ }^{4}$ Division of Gastroenterology, Department of Internal Medicine, Asan Medical Center, University of Ulsan College of Medicine, 88, Olympic-ro 43-gil, Songpa-gu, Seoul 05505, Korea

Full list of author information is available at the end of the article
}

light delivery should be accomplished using EUS guidance, and 2) PDT can be used to downstage the pancreatic cancer before surgical resection [6].

However, a fiber laser used for i-PDT might be fragile and costlier and cause light loss during endoscopic procedures due to multiple flexions of the fiber laser that are required [3]. Furthermore, an unexpected small volume of necrosis might occur because a small amount of blood around the tip of the fiber laser might reduce the transmission of light energy into the target tissue [2-4].

Recent advances in mini light-emitting diodes (LEDs) may have made possible the development of a miniaturized catheter for i-PDT. We hypothesized that the newly developed mini-LED catheter might enhance light transmission with higher efficiency and lesser light energy loss than the conventional fiber laser in pancreatic cancer xenografts.

Human pancreatic cancer BxPC-3 cell lines were used to establish xenograft models in BALB/c nude mice (male, 8 weeks old, Charles River, Yokohama, Japan). Two widely available photosensitizers (Photofrin, Concordia Laboratories Inc, St Michael, Barbados and Chlorin e6, Ce6, Frontier Scientific, UT, USA) were used. Photofrin ( $5 \mathrm{mg} / \mathrm{kg}$, porfimer sodium) was intravenously injected in mice having tumors larger than $8-10 \mathrm{~mm}$. The mice were kept in dark conditions for $24 \mathrm{~h}$, following which their tumors were treated with i-PDT through the conventional $(5 \mathrm{~mm}$-length conventional optical quartz diffuser, $630 \mathrm{~nm}$, power density of $300 \mathrm{~mW} / \mathrm{cm}^{2}$, $\left.100 \mathrm{~J} / \mathrm{cm}^{2}\right)$ or mini-LED catheter $(5 \mathrm{~mm}$-length diffuser, 
$630 \mathrm{~nm}$, power density of $8.5 \mathrm{~mW} / \mathrm{cm}^{2}$ ) in the Photofrin group. Intravenous administration of $\mathrm{Ce} 6(2.5 \mathrm{mg} /$ $\mathrm{kg}$, Frontier Scientific, UT, USA) and laser irradiation at $660 \mathrm{~nm}(5 \mathrm{~mm}$-length conventional optic quartz diffuser, power density of $300 \mathrm{~mW} / \mathrm{cm}^{2}, 100 \mathrm{~J} / \mathrm{cm}^{2}$ ) or min-LED catheter $(5 \mathrm{~mm}$-length diffuser, $650 \mathrm{~nm}$, power density of $9.1 \mathrm{~mW} / \mathrm{cm}^{2}$ ) were performed in the Ce6 group (Fig. 1A-D). In both groups, a dose de-escalating scheme was designed with a $100 \mathrm{~J} / \mathrm{cm}^{2}$ and $50 \mathrm{~J} / \mathrm{cm}^{2}$ in mini-LED based i-PDT for the evaluation of durable light intensity compared with conventional dose $\left(100 \mathrm{~J} / \mathrm{cm}^{2}\right)$ of fiber laser based i-PDT. Mice were divided into five treatment groups: i) Photofrin or $\mathrm{Ce} 6+$ conventional i-PDT with $100 \mathrm{~J} / \mathrm{cm}^{2}$; ii) Photofrin or Ce6+ mini-LED i-PDT with $100 \mathrm{~J} / \mathrm{cm}^{2}$; iii) Photofrin or Ce6 + mini-LED i-PDT with with $50 \mathrm{~J} / \mathrm{cm}^{2}$; iv) free Photofrin or Ce6+ mini-LED irradiation with $100 \mathrm{~J} / \mathrm{cm}^{2}$; and v) Photofrin or Ce6 alone. The changes in volume and size of xenograft tumors were measured within 15 days after i-PDT, and histopathologic examination was performed at the same time. For immunohistochemical analysis, the fixed tumor tissues were embedded in paraffin, sectioned $(4 \mu \mathrm{m})$ onto glass slides, and stained with anti-CD68 antibody (ab125212,
Abcam). Slides were scanned using the PerkinElmer Vectra Polaris Automated Quantitative Pathology Imaging System (Akoya Biosciences, Marlborough, MA), and images were analyzed using the inForm software and TIBCO Spotfire (Perkin-Elmer, Waltham, MA).

Among the treatment groups, mini-LED based i-PDT with Photofrin and Ce6 $\left(100 \mathrm{~J} / \mathrm{cm}^{2}\right)$ resulted in the smallest tumor volume after treatment, with a reduction by about $48 \%$ and $41 \%$, respectively, compared to the notreatment control group, followed by the conventional i-PDT $\left(100 \mathrm{~J} / \mathrm{cm}^{2}\right)$ with Photofrin (about $21 \%$ reduction), and Ce6 groups (about 17\% reduction) (Fig. 1D, E). Growth curves in the mini-LED based i-PDT (Photofrin, $100 \mathrm{~J} / \mathrm{cm}^{2}$ and $50 \mathrm{~J} / \mathrm{cm}^{2}$; Ce6, $100 \mathrm{~J} / \mathrm{cm}^{2}$ ) and conventional PDT (Photofrin $100 \mathrm{~J} / \mathrm{cm}^{2}$ ) groups were significantly different than those in untreated controls (Fig. 2A, B).

After PDT, the recruitment of macrophages was assessed by histologic analysis of the CD68 immunohistochemical staining for the evaluation of i-PDT based dead cell removal $[7,8]$. Tumors treated with mini-LEDbased i-PDT with Photofrin $\left(100 \mathrm{~J} / \mathrm{cm}^{2}\right)$ showed a significant increase in the recruitment of macrophages than in the untreated control group (Fig. 2C, D).

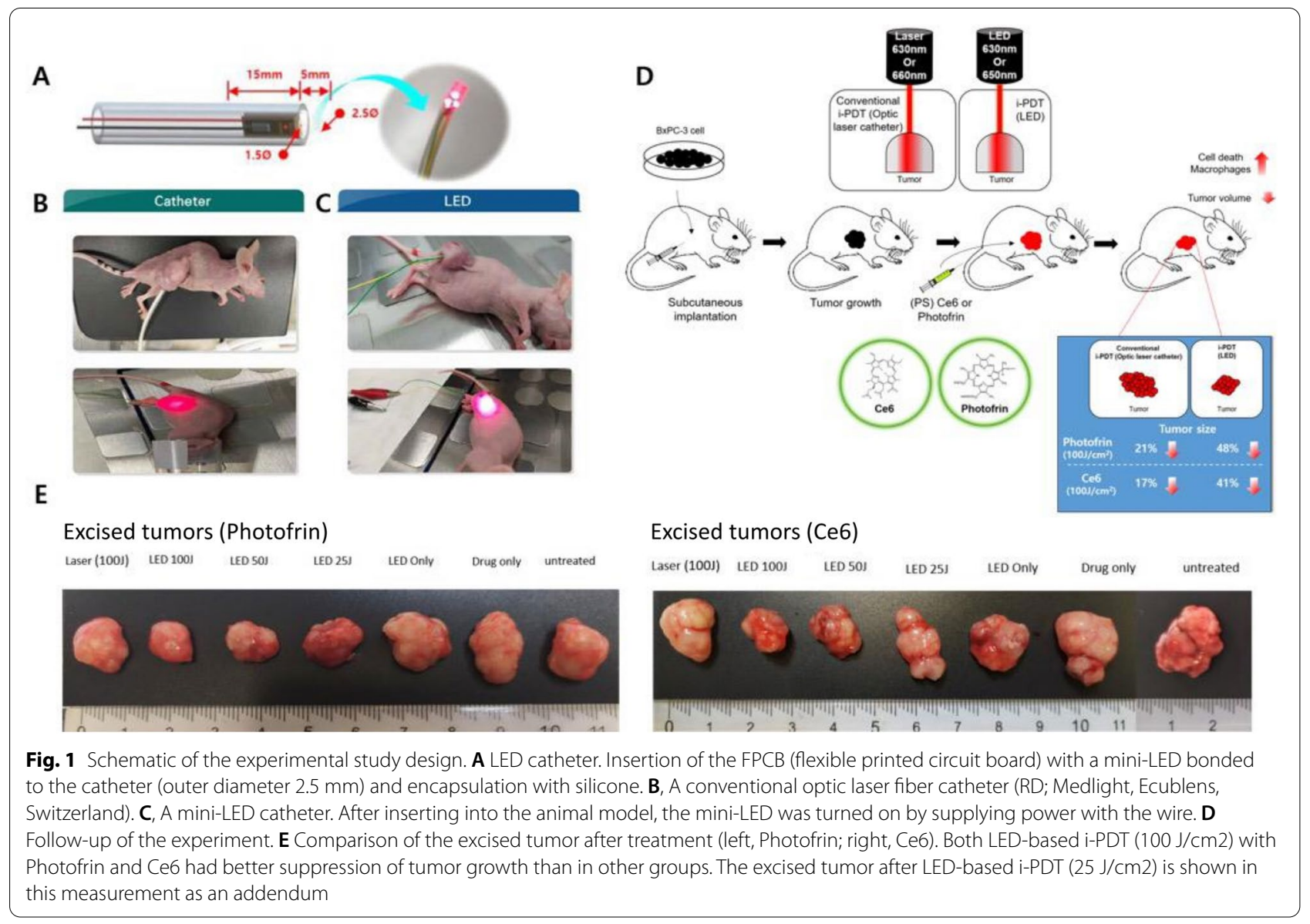




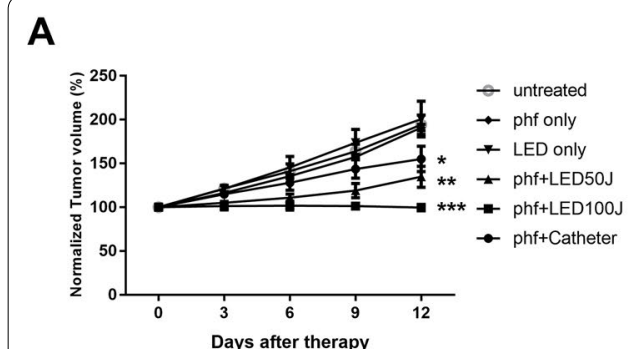

B

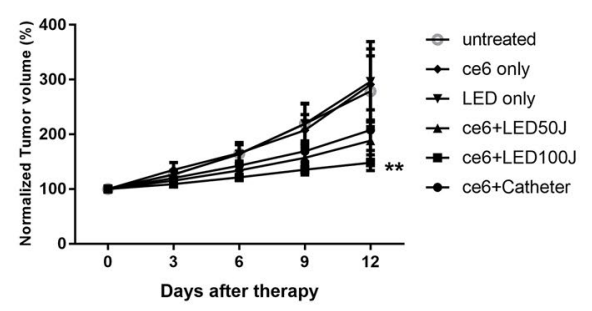

C

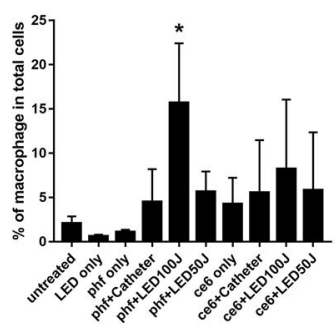

D
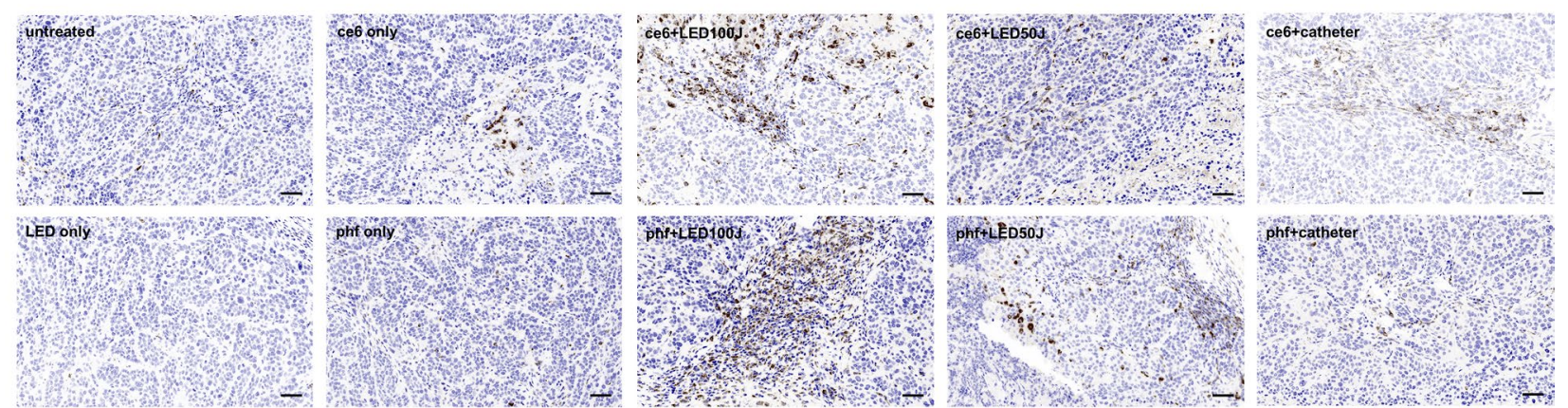

Fig. 2 In vivo efficacy of interstitial-photodynamic therapy (i-PDT) in BxPC3 tumor-bearing mice within 15 days in different groups treated with Photofrin (Phf) and chlorin e6 (Ce6). A, Normalized tumor volumes in mice treated with Phf+Catheter, Phf+LED100J, Phf+LED50J, LED only, and Phf only and untreated mice ( $n=4$ per group). B, Normalized tumor volumes in mice treated with Ce6+Catheter, Ce6+LED100J, Ce6+LED50J, LED only, and Ce6 only and untreated mice ( $n=4$ per group). C, Quantitative analysis of CD68-positive cells after indicated treatments. D, Representative images of CD68 staining. Scale bars: $50 \mathrm{~mm}$. Asterisks indicate $p$ values for the comparison of each group of irradiated tumors or nonirradiated tumors by one-way ANOVA. ${ }^{*} p<0.05 ;{ }^{* *} p<0.01 ;{ }^{* * *} p<0.001$

LEDs, unlike the conventional light sources, generate high levels of light with less heat; they have a compact structure and low cost and consume less electricity [9]. Mini-(100-200 $\mu \mathrm{m})$ or micro-LEDs (less than $100 \mu \mathrm{m}$ ) might have a greater clinical impact on wearable or implantable medical devices in terms of small size and application across various dimensions (9). In this preliminary report, 3 mini-LED chips ( 2 with side and 1 with forward firing) a with $2.5-\mathrm{mm}$ diameter and $5-\mathrm{mm}$ diffuser length catheter were used for administering PDT in pancreatic cancer xenografts (Fig. 1A).

This miniaturized LED catheter might have a better clinical impact, with a twofold higher suppression of tumor growth and cost advantage compared with fiber laser. Considering the better suppression of the tumor growth in mini-LED-based i-PDT with lower power density and light dose compared with conventional i-PDT, mini- or micro-LED-based miniaturized catheters might be a suitable and promising downstaging option for i-PDT with impactful light delivery in patients with pancreatic cancer treated with neoadjuvant chemotherapy. Development of further miniaturized mini- or micro-LED catheters less than $1 \mathrm{~mm}$ in diameter and diffuser length of $1 \mathrm{~cm}$ for EUSguided i-PDT is currently ongoing.

The mini-LED-based i-PDT with Photofrin and Ce6 showed promising antitumor effects in this pre-clinical study of xenografts of pancreatic cancer. Our data may provide preliminary evidence about the enormous potential of mini-LED-based i-PDT in patients with pancreatic cancer.

\section{Abbreviations}

PDT: Photodynamic therapy; EUS: Endoscopic ultrasound; LED: Light emitting diode; i-PDT: Interstitial PDT; Ce6: Chlorin e6.

\section{Acknowledgements}

We thank Gidong Sa, Jayeon Kim, Saung Kim, Jiho Jeong in Bio-Health Research Center, Korea Photonics Technology Institute, Gwangju, Korea, for technical support and Yoon Kyung Park for technical assistance.

\section{Authors' contributions}

DHP and SYK conceptualized and designed the experiments. SoYK, EC, and SB performed the experiments. SB and SYK analyzed data. SB and SYK did the statistical analysis. DHP, SYK, SoYK, and SB wrote the manuscript. All authors read and approved the final manuscript. 


\section{Funding}

This research was supported by the National Research Foundation (NRF) funded by the Ministry of Science and ICT (No. NRF-2020R1A2C2099718, and NRF-2018M3C1B9089117) This study was also supported by a Grant (2018IL0771) from the Asan Institute for Life Sciences, Asan Medical Center, Seoul, Korea.

\section{Availability of data and materials}

The datasets used and/or analysed during the current study are available from the corresponding author on reasonable request.

\section{Declarations}

\section{Ethics approval and consent to participate}

All animal procedures were approved by the Institutional Animal Care and Use Committee of the Asan Institute for Life Science (Protocol Number: 2019-12303, Seoul, Korea).

\section{Consent for publication.}

Not applicable.

\section{Competing interests}

The author declare that they have no competing interests.

\section{Author details}

${ }^{1}$ Asan Medical Center, Asan Institute for Life Sciences, University of Ulsan College of Medicine, Seoul, Korea. ${ }^{2}$ Department of Medical Science, Asan Medical Center, University of Ulsan College of Medicine, Seoul, Korea. ${ }^{3}$ Asan Medical Center, Asan Institute for Life Sciences, University of Ulsan College of Medicine, 88, Olympic-ro 43-gil, Songpa-gu, Seoul 05505, Korea. ${ }^{4}$ Division of Gastroenterology, Department of Internal Medicine, Asan Medical Center, University of Ulsan College of Medicine, 88, Olympic-ro 43-gil, Songpa-gu, Seoul 05505, Korea.

Received: 15 May 2021 Accepted: 21 May 2021

Published online: 07 June 2021

\section{References}

1. Huang J, Lok V, Ngai CH, Zhang L, Yuan J, Lao XQ, et al. Worldwide burden of, risk factors for, and trends in pancreatic cancer. Gastroenterology. 2021;160(3):744-54.

2. Huggett MT, Jermyn M, Gillams A, Illing R, Mosse S, Novelli M, et al. Phase I/II study of verteporfin photodynamic therapy in locally advanced pancreatic cancer. Br J Cancer. 2014;110(7):1698-704.

3. Choi JH, Oh D, Lee JH, Park JH, Kim KP, Lee SS, et al. Initial human experience of endoscopic ultrasound-guided photodynamic therapy with a novel photosensitizer and a flexible laser-light catheter. Endoscopy. 2015;47(11):1035-8.

4. DeWitt JM, Sandrasegaran K, O’Neil B, House MG, Zyromski NJ, Sehdev A, et al. Phase 1 study of EUS-guided photodynamic therapy for locally advanced pancreatic cancer. Gastrointest Endosc. 2019;89(2):390-8.

5. Blum NT, Zhang Y, Qu J, Lin J, Huang P. Recent advances in self-exciting photodynamic therapy. Front Bioeng Biotechnol. 2020;8:594491.

6. Wang KK, Donahue TR, Haber GB, DeWitt JM, Chang KJ, Shah RJ, et al. The use of photodynamic therapy in pancreatic cancer: consensus statement from an expert panel. Gastroenterology. 2017;152(5):498.

7. Korbelik M, Hamblin MR. The impact of macrophage-cancer cell interaction on the efficacy of photodynamic therapy. Photochem Photobiol Sci. 2015;14(8):1403-9.

8. Heusinkveld $\mathrm{M}$, van der Burg SH. Identification and manipulation of tumor associated macrophages in human cancers. J Transl Med. 2011;9:216.

9. Kirino I, Fujita K, Sakanoue K, Sugita R, Yamagishi K, Takeoka S, et al. Metronomic photodynamic therapy using an implantable LED device and orally administered 5-aminolevulinic acid. Sci Rep. 2020;10(1):22017.

\section{Publisher's Note}

Springer Nature remains neutral with regard to jurisdictional claims in published maps and institutional affiliations.
Ready to submit your research? Choose BMC and benefit from:

- fast, convenient online submission

- thorough peer review by experienced researchers in your field

- rapid publication on acceptance

- support for research data, including large and complex data types

- gold Open Access which fosters wider collaboration and increased citations

- maximum visibility for your research: over $100 \mathrm{M}$ website views per year

At BMC, research is always in progress.

Learn more biomedcentral.com/submissions 